\title{
Rancang Bangun Sistem Monitoring Kelembaban Tanah Menggunakan Wireless Sensor Berbasis Arduino Uno
}

\author{
Putri Asriya*, Meqorry Yusfi \\ Jurusan Fisika, FMIPA,Universitas Andalas \\ Kampus Unand, Limau Manis, Padang, 25163 \\ *asriya.pu3@gmail.com
}

\begin{abstract}
ABSTRAK
Telah dilakukan rancang bangun sistem monitoring kelembaban tanah menggunakan wireless sensor berbasis Arduino Uno. Rancangan perangkat keras sistem ini terdiri dari satu unit transmitter yang dilengkapi oleh sensor soil moisture SEN0114 V2 dan satu unit receiver. Semua unit dikendalikan dengan menggunakan Arduino Uno. Data kelembaban tanah dikirim oleh unit transmitter ke unit receiver menggunakan transceiver nRF24L01+ yang memanfaatkan gelombang radio sebagai media pengiriman. Hasil deteksi nilai kelembaban tanah pada sensor ditampilkan oleh LCD 2x16 karakter. Hasil pengujian sensor kelembaban tanah meperlihatkan bahwa hubungan antara tegangan keluaran sensor dengan kelembaban tanah pada moisture meter adalah linear dengan nilai regresi sebesar 0,9758. Berdasarkan pengujian transceiver, jarak terjauh pengiriman data yang dapat diterima oleh receiver di luar ruangan tanpa ada penghalang adalah $200,1 \mathrm{~m}$. Pada pengujian variasi sudut pengiriman, data dapat diterima oleh unit receiver pada sudut $\geq 26,56^{\circ}$. Apabila sudut lebih kecil dari $26,56^{\circ}$ data masih dapat diterima dengan adanya delay hingga sudut $11,31^{\circ}$.

Kata kunci: sensor soil moisture, kelembaban tanah, wireless, gelombang radio, nRF24L01+
\end{abstract}

\begin{abstract}
Design of soil moisture monitoring system using wireless sensor based on Arduino Uno has been conducted. The hardware system consists of a transmitter unit which was equipped with soil moisture sensor SEN0114 V2 and a receiver unit. All of units are controlled by using Arduino Uno. Soil moisture data was sent by transmitter unit to receiver unit using nRF24L01+ that used radio waves as transmission medium. Soil moisture value was displayed on LCD $2 x 16$ character. Sensor soil moisture calibration showed that correlation between sensor output voltage with soil moisture on moisture meter was linear with increasing water volume with regression value is 0.9758 . Based on transceiver test, the longest distance of transmission data can be accepted by receiver unit is $200.1 \mathrm{~m}$ at outdoor without any barriers. On angles transmission variation test, data can be received by receiver at angle $\geq 26.56^{\circ}$, if the angle is smaller than $26.56^{\circ}$ data can still be received up to $11.31^{\circ}$ with delay.

Keywords: soil moisture sensor, soil moisture, wireless, radio waves, nRF24LO1+
\end{abstract}

\section{PENDAHULUAN}

Indonesia sebagai negara agraris memiliki potensi yang sangat besar untuk meningkatkan pertumbuhan ekonomi di bidang industri pertanian. Kelembaban tanah merupakan salah satu faktor lingkungan yang mempengaruhi pertumbuhan tanaman. Kelembaban tanah dapat mempengaruhi kehidupan biologi di dalam tanah, seperti patogen tanah, tanaman inang, dan mikroorganisme lainnya dalam tanah. Kelembaban tanah yang tinggi dapat meningkatkan serangan penyakit yang disebabkan oleh Pythium sp. sehingga meningkatkan aktivitas zoospora (Yani, 1985). Untuk menyelesaikan permasalahan tersebut perlu adanya sistem monitoring yang memudahkan pengukuran kelembaban tanah salah satunya adalah dengan memanfaatkan piranti sensor dan wireless.

Metode standar yang digunakan untuk mengukur kelembaban tanah/kadar air tanah adalah metode termogravimetri, yaitu dengan mengeringkan tanah menggunakan oven pada suhu $105{ }^{\circ} \mathrm{C}$ yang telah diketahui massanya. Nilai kadar air diperoleh dengan membandingkan berat basah dan berat kering. Metode ini membutuhkan waktu yang cukup lama dan dapat merusak sampel tanah, juga tidak dapat digunakan untuk pengukuran berulang di lokasi yang sama (Walker, dkk, 2004). Wobschall dan Lakhsmanan (2005) telah merancang sensor kelembaban tanah yang terdiri atas sebuah elektrona berbahan dasar stainless steel. Sensor ini membaca kelembaban tanah berdasarkan perubahan nilai kapasitansinya. Namun, sensor ini hanya mampu mengukur kelembaban tanah dari $0 \%$ hingga $45 \%$. 
Chung, dkk (2013) telah memanfaatkan modul transceiver nRF24L01 untuk monitoring kelembaban tanah. Modul transceiver nRF24L01 ini cukup ekonomis dan membutuhkan daya yang rendah untuk beroperasi. Sensor kelembaban tanah yang digunakan adalah Decagon EC-5. Sensor ini mengukur kadar air tanah dari 0\% sampai 100\% dalam menentukan kelembaban tanah berdasarkan konstanta dielektrik tanah. Hasil keakuratan nilai output dibandingkan dengan membaca output dari perangkat lunak utilitas ECH-20 yang terhubung ke data logger EM5R. Namun, harga sensor Decagon EC-5 ini tidak ekonomis sehingga membutuhkan biaya yang cukup besa apabila melakukan pengujian di beberapa tempat. Pambudi, dkk (2014) telah merancang bangun wireless sensor network untuk monitoring suhu dan kelembaban pada lahan tanaman jarak. Penelitian tersebut menggunakan sensor DHT11 dan soil moisture sensor SEN0114 untuk mendeteksi suhu dan kelembaban pada lahan, sedangkan wireless yang digunakan adalah Xbee. Jarak maksimal untuk pengiriman data oleh Xbee pada penelitian tersebut adalah 100 meter untuk di luar ruangan.

Sonovane (2009) menjelaskan bahwa transceiver nRF24L01+ adalah sebuah modul komunikasi jarak jauh yang memanfaatkan pita gelombang Radio Frekuensi 2,4 GHz ISM (Industrial, Scientific and Medical). Modul ini menggunakan antarmuka SPI untuk berkomunikasi. NRF24L01 merupakan transceiver yang terdiri dari frequency synthesizer yang terintegrasi, power amplifier, osilator kristal, modulator, demodulator, dan enhanced shockburst protocol engine. Transmisi sinyal tanpa kabel menggunakan pemancar sebagai media untuk penyebaran sinyal informasi yang termodulasi dengan gelombang elektromagetik. Pemanfaatan gelombang elektromagnet dalam menyebarkan sinyal informasi memiliki keuntungan karena penjalaran gelombang elektromagnetik tidak membutuhkan medium transmisi. Sistem telemetri wireless terdiri atas 2 unit utama yaitu unit pemancar (transmitter) dan unit penerima (receiver). Pemancar menggunakan frekuensi gelombang radio pada prinsipnya mengirim sinyal modulasi yang ditransmisikan melalui media udara. Sinyal modulasi yang dipancarkan dibagian transmitter ke udara diterima oleh bagian receiver. Kemudian sinyal modulasi yang sudah diterima bagian penerima disalurkan ke input modulator untuk melalui proses selanjutnya sampai sinyal termodulasi tersebut menjadi sinyal informasi (Genubhy, 2008).

Pada penelitian ini, transceiver nRF24L01+ yang dilengkapi antena eksternal dan sensor soil moisture V2 SEN0114 dimanfaatkan sebagai komponen wireless sensor untuk merancang bangun sistem monitoring kelembaban tanah pada lahan pertanian. Sensor ini menggunakan dua konduktor untuk melewatkan arus melalui tanah, kemudian membaca nilai resistansi untuk mendapatkan tingkat kelembaban. Kemudahan yang diperoleh menggunakan wireless sensor ini, Petani tidak perlu ke lokasi untuk melakukan pengukuran kelembaban tanah karena data dari sensor soil moisture V2 SEN0114 yang mendeteksi nilai kelembaban tanah akan dikirimkan secara wireless oleh modul transceiver nRF24L01+ ke LCD pada lokasi base station.

\section{METODE}

Rancang bangun sistem monitoring kelembaban tanah menggunakan wireless sensor yang dilakukan meliputi perangkat keras (hardware) dan perangkat lunak (software). Perangkat keras terdiri dari unit transmitter dan unit receiver. Setiap Unit dilengkapi oleh catu daya $9 \mathrm{~V}$ dc, Arduino Uno, nRF24L01+ PA+LNA yang dilengkapi oleh antena eksternal, dan LCD 16x2 karakter. Sensor soil moisture V2 SEN0114 hanya dipasang pada unit transmitter.

\subsection{Diagram Blok Sistem}

Diagram blok sistem rancangan sistem monitoring secara keseluruhan dapat dilihat pada Gambar 1. Diagram blok sistem ini terdiri dari unit transmitter (Tx) dan unit receiver ( $\mathrm{Rx})$ yang masing-masing blok sudah digabung menjadi satu sistem. 


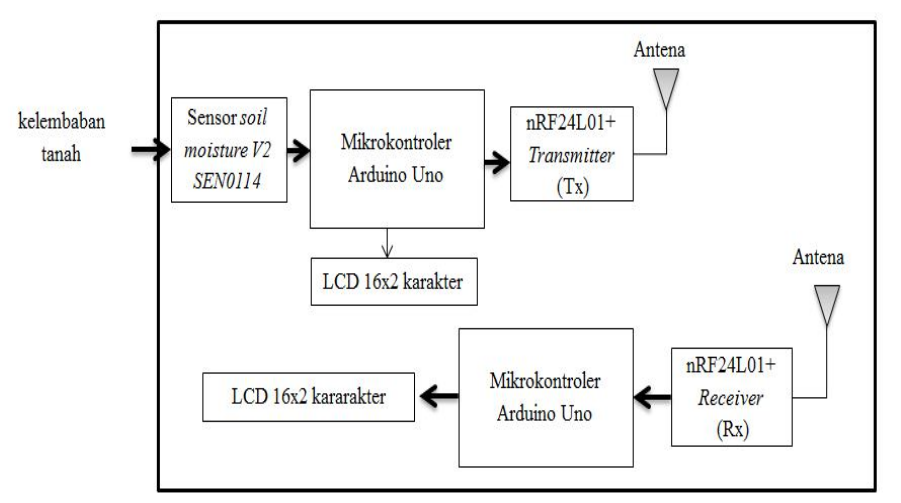

Gambar 1 Diagram blok sistem monitoring kelembaban tanah

\subsection{Rancangan Perangkat Keras Keseluruhan}

Rancangan perangkat keras secara keseluruahan terdiri dari 1 unit transmitter dan 1 unit receiver. Unit transmitter dilengkapi oleh sensor soil moisture V2 SEN0114. Prinsip kerja dari rancangan sistem ini diawali dengan penginderaan besaran oleh sensor, dimana kelembaban pada tanah diindera oleh sensor soil moisture V2 SEN0114. Keluaran sistem sensor ini berupa tegangan analog yang kemudian akan diolah oleh port ADC pada Arduino Uno untuk mengubah tegangan analog tersebut ke tegangan digital. Selanjutnya, Arduino Uno akan memproses untuk menampilkan nilai keluaran sensor ke display (LCD 2x16 karakter). Modul nRF24L01+ pada bagian transmitter yang telah menerima data dari Arduino Uno akan mengirimkan data tersebut secara wireless ke nRF24L01+ pada unit receiver dan menampilkan data tersebut pada display (LCD 2x16 karakter) yang berada pada area yang dijadikan sebagai base station. Rancangan perangkat keras dapat dilihat pada Gambar 2.

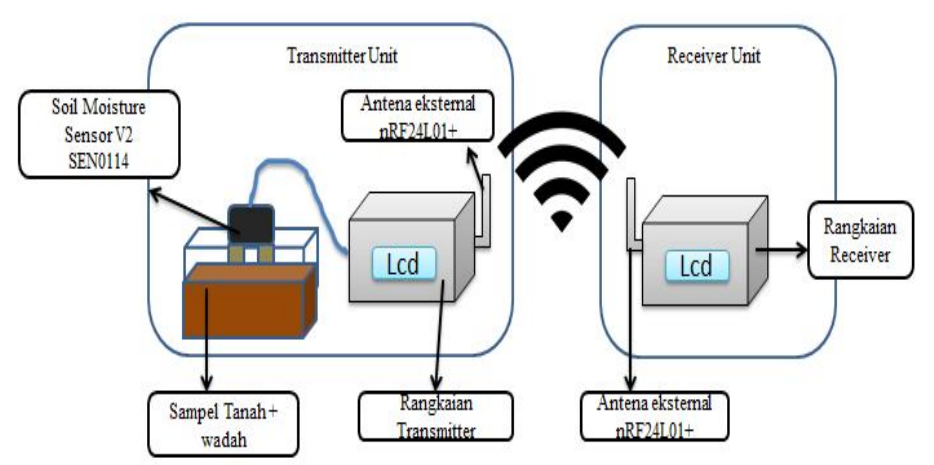

Gambar 2 Rancangan perangkat keras secara keseluruhan

\subsection{Rancangan Perangkat Lunak}

Pemrograman pada

perangkat lunak sistem yang akan ditanamkan pada Arduino Uno dirancang menggunakan software Arduino IDE. Software ini adalah sebuah compiler $C$ yang telah dilengkapi dengan fasilitas Integrated Development Environment (IDE) dan didesain agar dapat menghasilkan kode program secara otomatis untuk Arduino Uno.

\section{HASIL DAN DISKUSI}

\subsection{Pengujian Sensor Soil Moisture V2 SEN 0114}

Pengujian awal sensor soil moisture V2 SEN 0114 sebagai pendeteksi kelembaban tanah dilakukan dengan melihat perbandingan antara tegangan keluaran pada sensor dengan nilai kelembaban tanah pada alat ukur pembanding (Moisture Meter). Pengujian dilakukan dengan memberikan penambahan volume air pada tanah dengan variasi $10 \mathrm{~mL}$ hingga $100 \mathrm{~mL}$ yang bermassa sebesar $375 \mathrm{~g}$. Data tegangan keluaran dari sensor diambil untuk setiap variasi 
volume air dengan menggunakan multimeter digital. Perubahan kelembaban tanah terjadi setiap penambahan volume air pada tanah. Kenaikan tegangan keluaran sensor kelembaban tanah (soil moisture sensor V2 SEN0114) terjadi seiring bertambahnya volume air sehingga persentase nilai kelembaban tanah juga meningkat. Hasil hubungan antara tegangan keluaran sensor dengan kelembaban tanah terukur dapat dilihat pada Gambar 3.

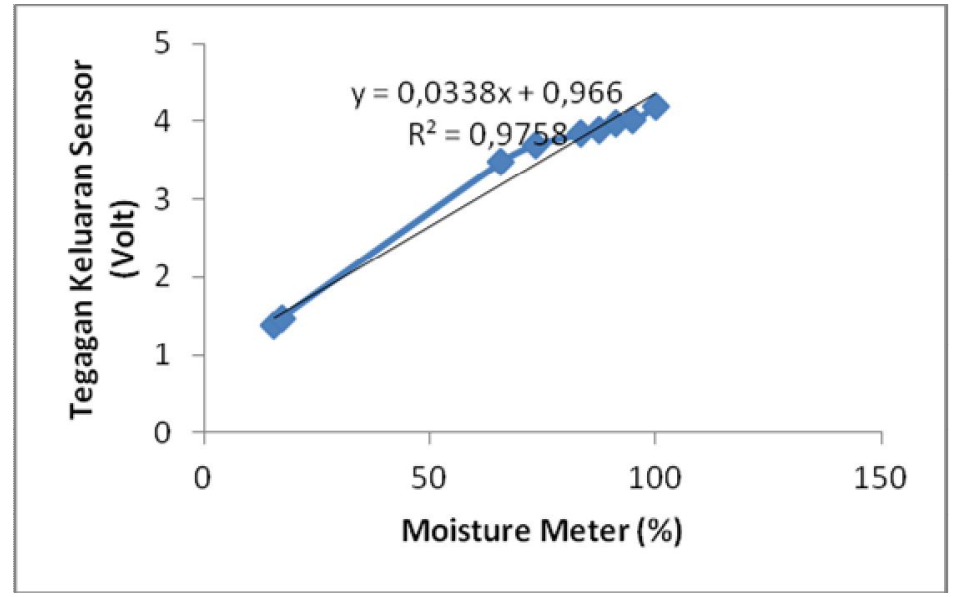

Gambar 3 Hubungan antara tegangan keluaran dengan kelembaban tanah

Berdasarkan Gambar 3 hasil regresi linear antara tegangan keluaran dengan kelembaban tanah pada alat ukur yaitu $y=0,0338 x+0,966 . x$ merupakan nilai kelembaban tanah dan $y$ adalah tegangan keluaran dari sensor kelembaban tanah sedangkan angka 0,966 menyatakan nilai tegangan awal sensor saat nilai kelembaban tanah pada moisture meter mendekati nol. Tanda positif (+) menyatakan bahwa tegangan keluaran naik dengan peningkatan nilai persen kelembaban tanah pada moisture meter. Hasil derajat kolerasi linear grafik diperoleh sebesar $R^{2}=0,9758$. Nilai ini sudah menunjukkan bahwa hubungan antara tegangan keluaran sensor dengan nilai kelembaban tanah pada alat ukur adalah linier.

\subsection{Pengujian Transceiver nRF24L01+}

\subsubsection{Pengujian Pengiriman Data di Luar Ruangan}

Pengujian transceiver nRF24L01+ dilakukan di luar ruangan untuk melihat seberapa jauh wireless mampu mengirimkan data. Selang waktu pengiriman data telah diprogram setiap $2000 \mathrm{~ms}$ atau $2 \mathrm{~s}$. Pada unit transmitter (Tx) telah dilengkapi dengan sensor soil moisture yang akan mendeteksi kelembaban tanah pada sampel tanah yang bermassa $400 \mathrm{~g}$ dan mengirimkannya ke unit receiver (Rx). Hasil pengujian dapat dilihat pada Tabel 1.

Tabel 1 Hasil pengujian pengiriman data kelembaban tanah di luar ruangan

\begin{tabular}{cccc}
\hline No. & Jarak (m) & Tx & Rx \\
\hline 1. & 10,0 & $34 \%$ & $34 \%$ \\
2. & 50,0 & $34 \%$ & $34 \%$ \\
3. & 100,0 & $34 \%$ & $34 \%$ \\
4. & 150,0 & $34 \%$ & $34 \%$ \\
5. & 200,0 & $34 \%$ & $34 \%$ \\
6. & 200,1 & $42 \%$ & $42 \%$ \\
7. & 201,0 & $42 \%$ & - \\
8. & 250,0 & $42 \%$ & - \\
\hline
\end{tabular}

Berdasarkan hasil pengujian pada Tabel 1 dapat dilihat bahwa data yang diterima oleh unit receiver sudah sama dengan yang dikirimkan oleh unit transmitter. Kemampuan transceiver untuk mengirimkan data hanya sejauh $200,1 \mathrm{~m}$. Pada jarak besar dari 200,1 $\mathrm{m}$ data tidak ada yang diterima oleh unit receiver. Hal ini terjadi karena adanya pelemahan energi sinyal yang terpancar seiring semakin jauhnya jarak penerima. Pengaruh dari pelemahan energi dari gelombang elektromagnetik ini memperlihatkan bahwa semakin jauh jarak antara Tx dan 
Rx akan menganggu keefektifan suatu sinyal untuk membawa informasi. Pada pengambilan data terdapat beberapa gangguan lain yang dapat menghambat kinerja perambatan gelombang radio, yaitu kendaraan yang lewat dan pepohonan disekitar area pengambilan data.

\subsubsection{Pengujian Berdasarkan Variasi Sudut Pengiriman}

Teknis pengujian berdasarkan sudut pengiriman dilakukan dengan meletakkan $\mathrm{Rx}$ di gedung dengan ketinggian $5 \mathrm{~m}$, sedangkan Tx diletakkan pada halaman bawah. Ilustrasi pengambilan data dapat dilihat pada Gambar 4 dan hasil pengujian dapat dilihat pada Tabel 2.

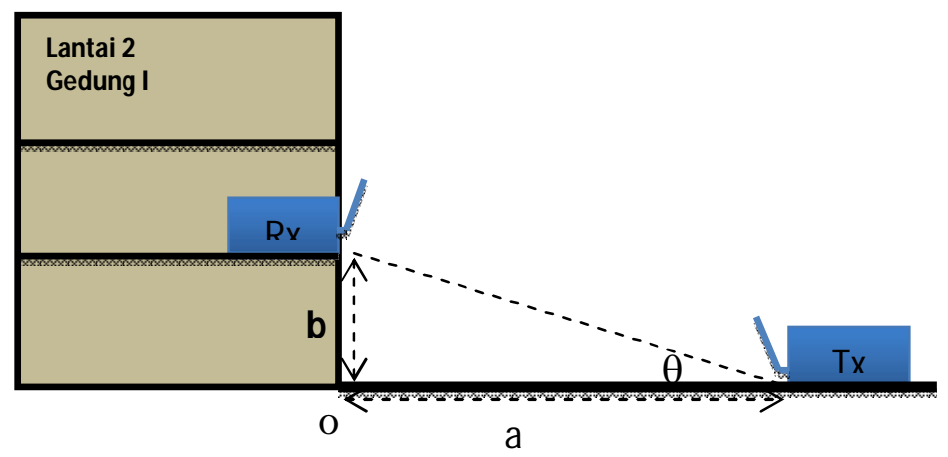

Gambar 4 Ilustrasi pengambilan data untuk variasi sudut

Pada Tabel 2 , besar sudut minimum yang dibentuk untuk memperoleh data pengiriman tanpa terputus adalah sebesar $26,56^{\circ}$. Apabila sudut yang dibentuk kecil dari $26,56^{\circ}$ data yang dikirimkan $\mathrm{Tx}$ masih dapat diterima oleh $\mathrm{Rx}$ hingga sudut $11,31^{\circ}$, namun dengan adanya penambahan delay penerimaan data oleh Rx. Delay atau penundaan waktu pengiriman data ini mengakibatkan data yang diperoleh lebih lambat karena kecepatan sinyal melalui panjang lintasan yang berbeda sehingga mempengaruhi waktu kedatangan sinyal.

Tabel 2 Hasil pengujian nRF24101+ berdasarkan variasi sudut pengiriman

\begin{tabular}{cccccc}
\hline \multirow{2}{*}{ Posisi Tx (a) } & \multirow{2}{*}{ Posisi Rx (b) } & \multirow{2}{*}{ Sudut $(\boldsymbol{\theta})$} & \multicolumn{2}{c}{ Kelembaban Tanah } & \multirow{2}{*}{ Delay } \\
\cline { 4 - 5 } & & & $\mathbf{T x}$ & $\mathbf{R x}$ & \\
\hline $1 \mathrm{~m}$ & $5 \mathrm{~m}$ & $78,69^{\circ}$ & $12 \%$ & $12 \%$ & 0 \\
$4 \mathrm{~m}$ & $5 \mathrm{~m}$ & $51,34^{\circ}$ & $12 \%$ & $12 \%$ & 0 \\
$7 \mathrm{~m}$ & $5 \mathrm{~m}$ & $35,53^{\circ}$ & $12 \%$ & $12 \%$ & 0 \\
$10 \mathrm{~m}$ & $5 \mathrm{~m}$ & $26,56^{\circ}$ & $12 \%$ & $12 \%$ & 0 \\
$13 \mathrm{~m}$ & $5 \mathrm{~m}$ & $21,03^{\circ}$ & $12 \%$ & $12 \%$ & $5 \mathrm{~s}$ \\
$16 \mathrm{~m}$ & $5 \mathrm{~m}$ & $17,35^{\circ}$ & $12 \%$ & $12 \%$ & $2,5 \mathrm{~s}$ \\
$19 \mathrm{~m}$ & $5 \mathrm{~m}$ & $14,74^{\circ}$ & $12 \%$ & $12 \%$ & $2,5 \mathrm{~s}$ \\
$22 \mathrm{~m}$ & $5 \mathrm{~m}$ & $12,80^{\circ}$ & $12 \%$ & $12 \%$ & $2,4 \mathrm{~s}$ \\
$25 \mathrm{~m}$ & $5 \mathrm{~m}$ & $11,31^{\circ}$ & $12 \%$ & $12 \%$ & $2,2 \mathrm{~s}$ \\
$28 \mathrm{~m}$ & $5 \mathrm{~m}$ & $10,12^{\circ}$ & $12 \%$ & - & - \\
\hline
\end{tabular}

\subsubsection{Pengujian Keseluruhan}

Pengujian alat secara keseluruhan sudah meliputi pengujian hardware dan software. Pengujian dilakukan dengan meletakkan Tx yang sudah dilengkapi sensor soil moisture dan menancapkan sensor ke tanah sawah. Pengujian dilakukan dengan mengirimkan nilai kelembaban tanah pada unit Tx ke unit Rx tanpa halangan dengan jarak pengiriman sebesar 35 m. Hasil pengujian dapat dilihat pada Tabel 3 . 
Tabel 3 Hasil pengujian sistem keseluruhan di sawah

\begin{tabular}{cccc}
\hline \multicolumn{2}{c}{ Kelembaban Tanah } & $\begin{array}{c}\text { Moisture Meter } \\
(\boldsymbol{\%})\end{array}$ & $\begin{array}{c}\text { Error } \\
(\boldsymbol{\%})\end{array}$ \\
\cline { 1 - 2 } $\mathbf{T x}(\boldsymbol{\%})$ & $\mathbf{R x}(\boldsymbol{\%})$ & 79,6 & 2,01 \\
78 & 78 & 79,6 & 2,01 \\
78 & 78 & 79,6 & 3,27 \\
77 & 77 & 79,6 & 3,27 \\
80 & 77 & 80,8 & 0,99 \\
80 & 80 & 80,8 & 0,99 \\
78 & 80 & 80,8 & 3,47 \\
78 & 78 & 80,8 & 3,47 \\
80 & 78 & 80,8 & 0,99 \\
80 & 80 & 80,8 & 0,99 \\
\hline \multicolumn{4}{c}{ Rata-rata persentase error } \\
\hline
\end{tabular}

Hasil pengujian pada Tabel 3 menunjukkan bahwa pengukuran kelembaban tanah menggunakan sensor soil moisture memperoleh nilai error yang relatif kecil yaitu rata-rata persentase kesalahan sebesar $2,15 \%$. Perbedaan nilai pengukuran yang diperoleh antara sensor dengan alat ukur moisture meter disebabkan oleh adanya perubahan tegangan keluaran yang tidak stabil pada sensor.

Berdasarkan hasil pengujian tersebut, agar data yang dikirimkan oleh Tx diterima dengan lancar oleh Rx sebaiknya posisi nRF24L01+ tidak berada pada kondisi terhalang dan posisi Tx dan Rx berada pada ketinggian yang sama. Adanya penghalang yang semakin banyak akan menyebabkan energi yang diperlukan sinyal untuk merambat semakin besar sehingga sebelum sinyal mencapai receiver energi sudah semakin kecil dan penerimaan informasi sinyal terganggu. Pada pengujian untuk ketinggian yang berbeda antara Tx dan Rx jangkauan jarak penerimaan data lebih kecil dibandingkan dengan posisi Tx dan Rx dengan ketinggian sama.

\section{KESIMPULAN}

Berdasarkan hasil dan analisis yang telah dilakukan, dapat disimpulkan bahwa hasil rancagan sistem monitoring kelmbaban tanah ini sudah dapat digunakan untuk memonitoring lahan pertanian. Hasil pengujian sensor soil moisture V2 SEN0114 dapat digunakan untuk mengukur kelembaban tanah dengan regresi linear sebesar 0,9758. Transceiver nRF24L01+ yang digunakan dapat mengirimkan data tanpa terputus dengan jarak pengiriman terjauh 200,1 $\mathrm{m}$ di luar ruangan. Pengiriman data berdasarkan variasi sudut pengiriman dapat diterima oleh Rx dengan sudut besar sama dengan $26,56^{\circ}$, untuk sudut lebih kecil dari $26,56^{\circ}$ data masih dapat diterima dengan adanya delay penerimaan sampai sudut $11,31^{\circ}$.

\section{DAFTAR PUSTAKA}

Chung, Wen-Yaw, Jocelyn F.V., dan Janine Tan, 2013, Wireless Sensor Network Based Soil Moisture Monitoring System Design, Papers of the 2013 Federated Conference on Computer Science and Information Systems National Science Council, Taiwan, hal 7982.

Pambudi, K.W., Jusak, Pauladie S., 2014, Rancang Bangun Wireless Sensor Network untuk Monitoring Suhu dan Kelembaban pada Lahan Tanaman Jarak, Journal of Control and Network System, Vol. 3. No.2, STIKOM Surabaya, hal. 09-17.

Genubhy, Afira, 2008, Pengukuran Karakteristik Propagasi Kanal VHF pada Band, Orbcomm, Jurnal Jurusan Teknik Elektro-FTI, Institut Teknologi Surabaya.

Sonavane, S.S., V. Kumar, B.P. Patil, 2009, MSP430 and nRF24L01 based Wireless Sensor Network Design with Adaptive Power Control, ICGST-CNIR Journal, Volume 8, ICGST, hal 11-15.

Walker, J.P., Garry R.W., dan Jetse D.K., 2004, In Situ Measurement of Soil Moisture: A Comparison of Technique, Journal of Hydrology, 293., University of Newcastle, hal 8599. 
Wobschall, Darold dan Deepak Lakhsmanan, 2005, Wireless Soil Moisture Sensor Based in Fringing Capacitance, IEEE, ISBN : 0-7803-9056-3.

Yani,M., 1985, Pengaruh Kelembaban Tanah, Pupuk N dan Pupuk P terhadap Mati Kecambah (Phythium sp.) pada Tanaman Cabai (Capsicum annuum L.) Suatu Uji Rumah Kaca, Skripsi, Fakultas Pertanian, Institut Pertanian Bogor, Bogor. 